\title{
Real scale experimental study for performance evaluation of unidirectional air diffuser perforated panels
}

\author{
Laurenţiu Tăcutu ${ }^{1}$, Ilinca Nastase $^{1 *}$,Vlad Iordache $^{1}$, Tiberiu Catalina ${ }^{1}$ and Cristiana Verona Croitoru ${ }^{1}$ \\ ${ }^{l}$ CAMBI, Technical University of Civil Engineering in Bucharest, Building Services Department, 66 Avenue PacheProtopopescu; \\ 020396, Bucharest, Romania; * correspondent author
}

\begin{abstract}
Nowadays, there is an increasing emphasis on indoor air quality due to technological evolution and the fact that people spend most of the time in enclosed spaces. Also, energy efficiency is another related factor that gains more and more attention. Improving air distribution in an enclosure can lead to achieve these goals. This improvement can be done by adjustingthe air terminals position, theredimensions or the air diffuser perforations. The paper presents the study of 8 types of panels with different perforations shapes. The systems were characterized by flow, pressure loss and noise. Usualand special geometries were chosen, all having the same flowsurface. The perforated panels were mounted in a unidirectional air flow (UAF)diffuser, also called a laminar air flow (LAF)diffuser, that is placed in a real scale operating room (OR) in our laboratory. The purpose of this study is to determine whether changing the shape in the perforated panels can improve the technical parameters of the diffuser.
\end{abstract}

\section{Introduction}

In modern days most of the buildings, whether they arecommercial, residential or industrial, have mechanical ventilation systems for improving air quality in their premises[1,2]. The systems, commonly referee to as HVAC systems, have the purpose toimprove indoor air quality and thermal comfort.To reach these goal, air parameters and air distribution are adjusted in accordance.Adjusting the air parametersrepresents an approach that is frequently called as an active method, while modifying the air distribution by changing the geometries in the perforated panelsis usuallyreferred as a passive method.Optimizing theair distributionin a space is achieved by adapting the air terminals units to the specifics of the space. This means to choose the optimal position for the air terminals and to select the right dimension and geometry for the diffuser. It is well recognised the fact that air distribution has an influence on thermal comfort, indoor air quality or even energy efficiency[3]. This also influences aerosol distribution, an important parameter in ORs and clean rooms. The paperpresents the study of 8 types of panels with different perforations shapes, mounted in an air terminal unit. For each panel, the following technical parameters were determined: flow, pressure loss, noise.

Analysing these technical parameters represents the first step in determining how the geometry of the perforations in panels affects the air distribution in a room. The perforated panelshave been mounted on a unidirectional air flow (UAF) $[4,5]$ or laminar air flow (LAF)[6]diffuser that isinstalled in the ventilation system of a real scaleOR in our laboratory.Future research on these panelswill take in to account their performance in terms of thermal comfort. The thermal comfort measurements will bemade in the same climaticchamber. The equivalent temperature, PMV and PPD indices will be determined with the help of two humanoid thermal manikins and a ComfortSense equipment.

\section{Experimental method}

These measurements were made in a climatic chamber that simulates a real scale OR, which has the dimensions of $3.5 \times 3.5 \times 2.5 \mathrm{~m}(1 \times \mathrm{LxH})$, temperature control on each wall and air ventilation system with an UAF diffuser. There were 8 types of panels analysed. The geometries selected were common ones, but also some special ones (Fig.1).For an easier reference, the panels were numbered with letters (Fig. 1, Table 1).

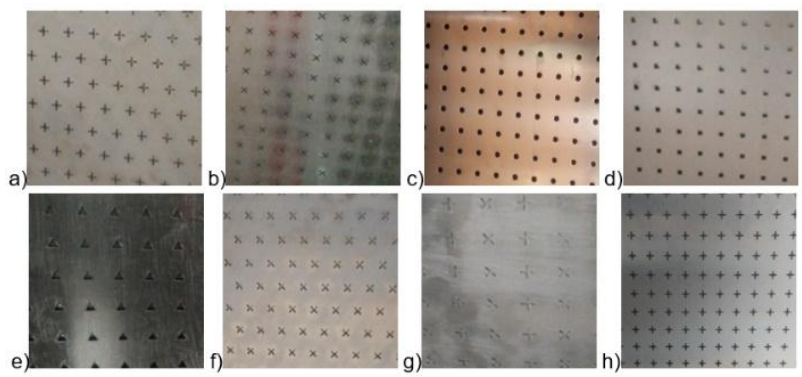

Figure 1. The geometriesof the panels

The special geometries were developed in previous studieswhere it was analysed, by numerical and experimental approaches, the flowing through such shapes[7-9]. Thepanels are made from analuminium sheet with the thickness of $1.5 \mathrm{~mm}$. A paneldimension is

*Corresponding author: ilinca.nastase@,gmail.com 
$1255 \times 635 \mathrm{~mm}$. For covering the whole surface of the diffuser, it requires 4panels, resulting in a total of 32 pieces. The free flow surface for each shape is approximately $19.625 \mathrm{~mm}^{2}(\mathrm{Sff})$ and the free flow areafor eachpanel is approximately $0.45 \mathrm{~m}^{2}$ (Aff). All 4 panels, with the same perforations, were mounted at the same time and measurements were made on the whole surface of the UAF diffuser. In the middle of the UAF diffuser, on the entire length, is a lamp with the width of $\approx 120$ $\mathrm{mm}$. Inside, the plenumis organized as follow: an enclosure at the upper part in which air is supplied, panelswith round holesat the lower part of this enclosure for stabilizing the flow, a second enclosure that represents the space for mounting the HEPA (high efficiency particulate air) filters and afterthe perforated panels are mounted. For these measurements there were no HEPA filters mounted.

Table 1. Panel geometries and notations

\begin{tabular}{|c|c|c|c|}
\hline No. & Panel type & Fig.1 & Notation \\
\hline 1 &,+ , intercalated & a) & $\mathrm{A}$ \\
\hline 2 & ,x" in line & b) & $\mathrm{B}$ \\
\hline 3 & ,O” & c) & $\mathrm{C}$ \\
\hline 4 & , 口" & d) & $\mathrm{D}$ \\
\hline 5 &,$\Delta "$ & e) & $\mathrm{E}$ \\
\hline 6 & ,X” intercalated & f) & $\mathrm{F}$ \\
\hline 7 & , ," and ,X” & g) & G \\
\hline 8 &,$+"$ & h) & $\mathrm{H}$ \\
\hline
\end{tabular}

The ventilation system consists in an axial fan, ducts and fittings, air flow regulators, plenumwith grillesand an automation system with a frequency converter mounted near the chamber.To have the same flow rate in the system,identical frequencies where selected when each type of panel was measured. The frequencies where selected to provide a minimum flow which the equipment can measure, not smaller than their error of measurement,and to allow at least 6 measurements across the entire range of the converter. The frequencies used for the measurements were $10.3 \mathrm{~Hz}, 19.2 \mathrm{~Hz}$, $26.5 \mathrm{~Hz}, 34.5 \mathrm{~Hz}, 40.6 \mathrm{~Hz}, 44.6 \mathrm{~Hz}, 45.3 \mathrm{~Hz}$ or $\max$, on a Danfoss converter, type VLT HVAC Basic. a)

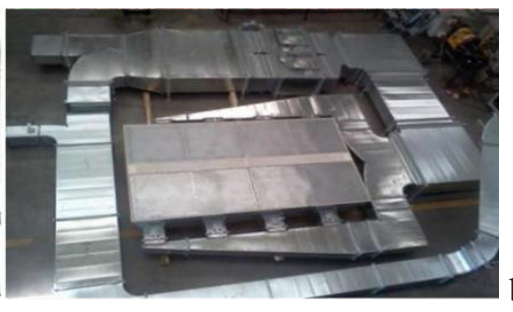

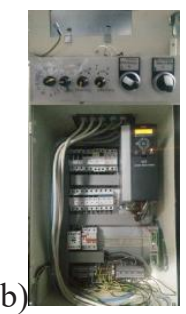

Figure 2. a) Ventilation system; b) Frequency converter

The air flow was measured byusing a balometer from TSI, type EBT720/EBT721, with a hood of 610x610mm made out of textile. The hood has almost the same width as a panelbut only a half of its length. Two types of such balometers were used forverifying if there are any perturbations between the values obtained from measuring with only one equipment and measuring with both at the same time. There were no significant differences between the values obtained, and the onesobserved can be dueto measurement errors. Also, the balometers were positioned on different areas of the
UAF diffusersurface. These measurements revealed that each panel had almost the same flow rate, regardless of his position in the UAF diffuser. This means that the aeraulic balancing of the ventilation system was done well. For minimizing air leaks between the panel and the frame of the diffuser, a sealing was made with black duct tape that behaves like a sponge.

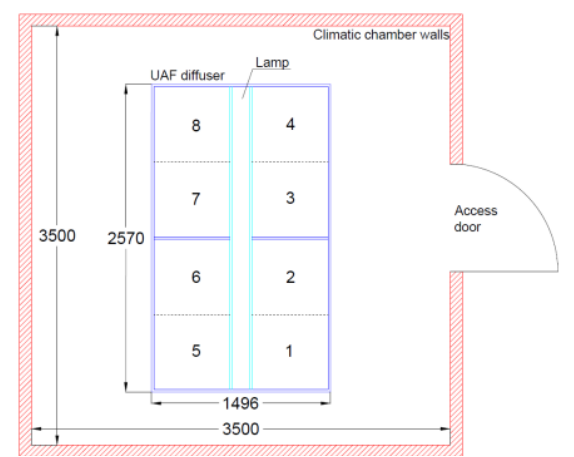

Figure 3. General sketch, top view, at real scale dimensions with the UAF diffuser and climatic chamber

Number notation (from 1 to 8 ) represents a measurement surface that can be covered by the hood of a balometer. The surface of a panel covers two notations (1 and 2). A total of 8 measurement surfaces for air flow have resulted on the surface of the UAF diffuser.

The pressure loss for each panel was measured by using a differential pressure manometer from Testo, type 521, in which two hoseswere connected.For measuring the pressure loss generated by each panel, one of the hose was mounted before the panel, inside of the plenum, in the space were the HEPA filters had to be mounted. The second hose was mounted after the panel, in the room. The door of the climatic chamber was closed during all measurements.

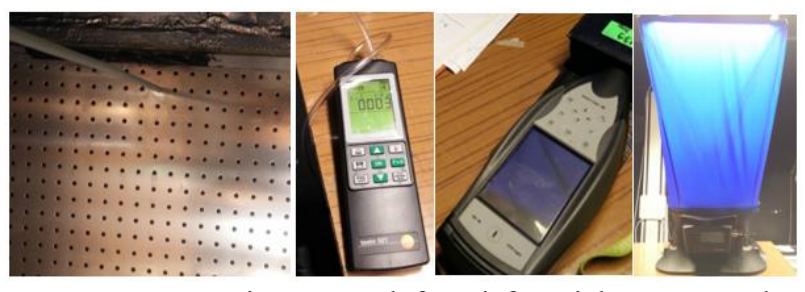

Figure 4. Equipment used, from left to right: a mounted hose and the manometer, sound meter, balometer

For sound measurements a portable sound meter from Bruel\&Kajer, type 2250-S, was used. The sound measurements were made at a height that corresponds to medical staff, $\approx 1.8 \mathrm{~m}$, and at a height that corresponds to patient, $\approx 1 \mathrm{~m}$. For each height there was four measurement points, each point was placed in the middle of each panel. The acoustic measurements were made also without panels, to determine if they generate or attenuate the sound. The sound measurements were made predominantly in periods without any activity in the laboratory (night or morning), but there were also some that could be done only during the day.

The value obtained for each measurement is an average value over a $10 \div 20$ s interval. The measurements were made starting with the lowest frequency, determining the flow, followed by the pressure lossmeasurement, ending with acoustic measurements. Tests were made for 
verifying if there are any differences between the values obtained when going ascending or descending on the frequency converter.No significant differences were observed between the values obtained and the ones observed can be due to reading or measurement errors.

\section{Results and comments}

Because no attenuationhas been implemented to eliminate the noise from the fan, noise levels resulted to be high. Also, due to this fact it will be wrong to assume that the technical characterization refers only to the panels, but rather they would representthe entire system (panel and ventilation system). Each system has beencharacterized, based on the values obtained, by pressure loss, noise and air flow. Charts for every system with these technical parameters were made. These charts are similar with the ones that can be found indiffusers datasheet. An example of such chart, with noise values for $1.8 \mathrm{~m}$ and $1 \mathrm{~m}$ height, can be seen in Fig. 4 and Fig. 5, for the ventilation system with panel type A.

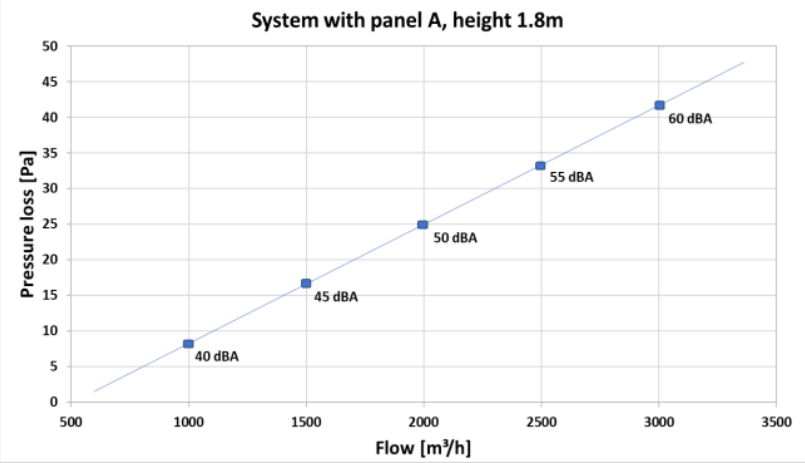

Figure 5. Ventilation system with panel type A, noise $1.8 \mathrm{~m}$

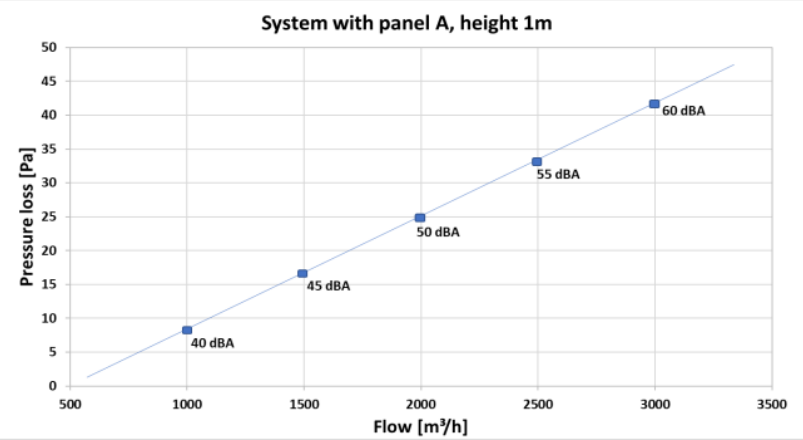

Figure 6. Ventilation system with panel type A, noise $1 \mathrm{~m}$

Presenting the data in this manner it's easier to read and allows the user to determine the other two parameters by only knowing one of them. A first comparation regarding the noise level measurements was made between the values obtained at $1.8 \mathrm{~m}$ and $1 \mathrm{~m}$ height. All systems have charts with the same allure, that's why only some comparations are presented here (Fig. $7 \div 10$ ). It was observed that there is only a slight difference between the values measured at these two heights, with a difference of $2 \mathrm{~dB}$ in average. The peaks that can be observed in the left part of the charts, at low flow rates, are due to environmental disturbances that happened outside. At this flow rates the ventilation system does not generate a lot of noiseand any small noisesfrom outside the climatic chamber,generated in the same time with the measurements, are adisturbing factor.

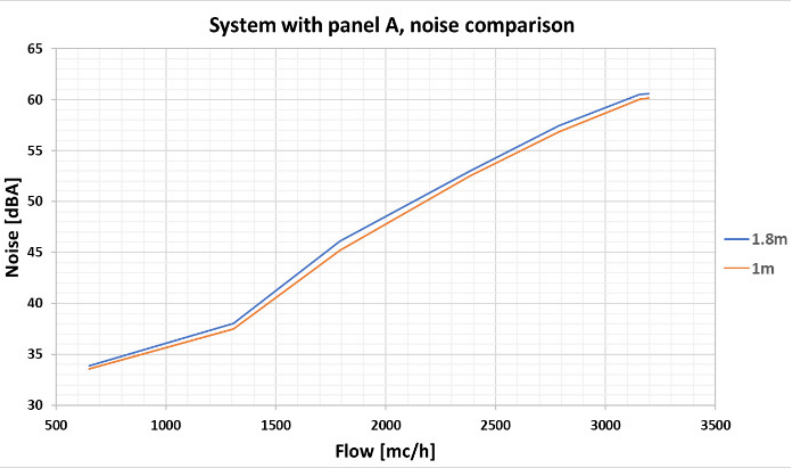

Figure 7. Noise comparationwith panel A, $1.8 \mathrm{~m}$ and $1 \mathrm{~m}$

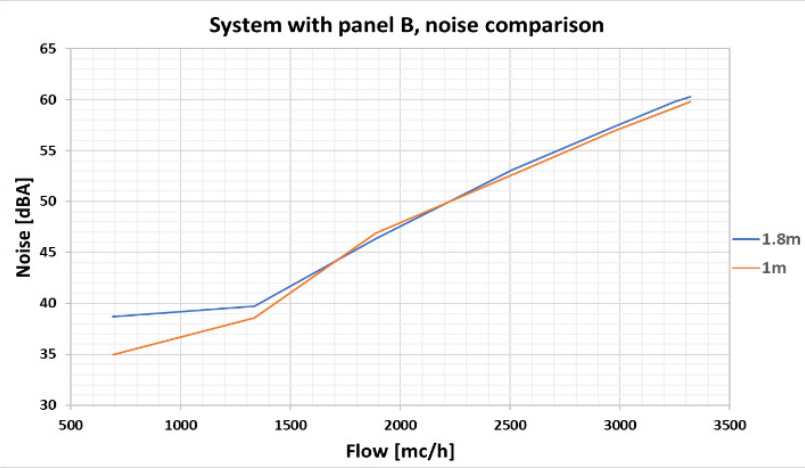

Figure 8. Noise comparation with panel B, $1.8 \mathrm{~m}$ and $1 \mathrm{~m}$

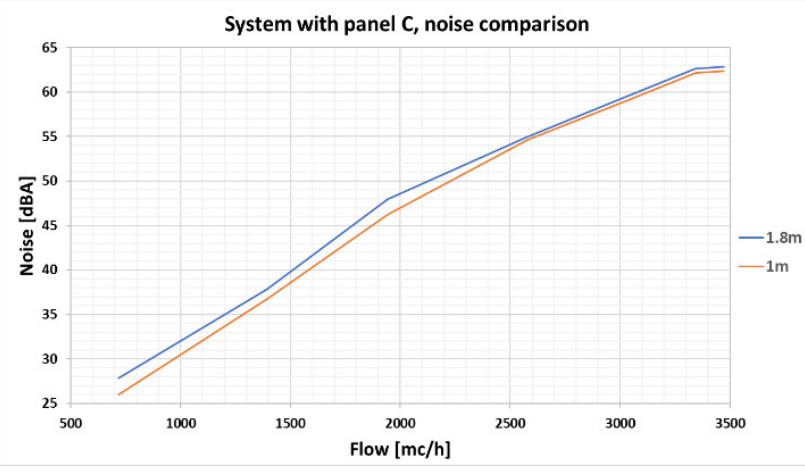

Figure 9. Noise comparation with panel C, $1.8 \mathrm{~m}$ and $1 \mathrm{~m}$

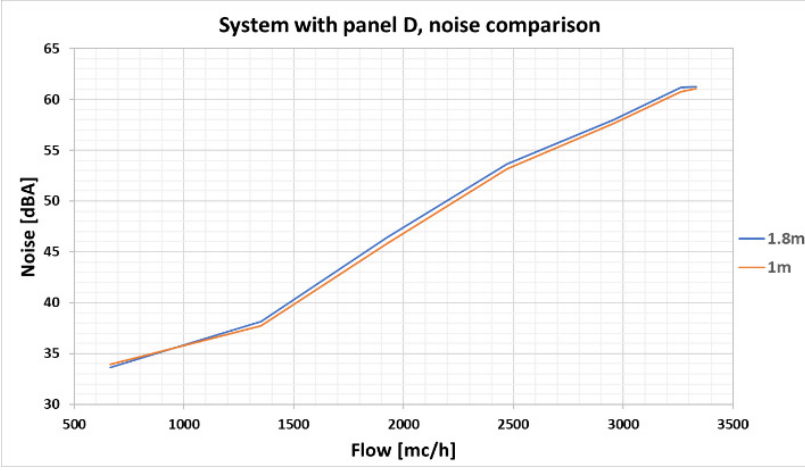

Figure 10. Noise comparation with panel D, $1.8 \mathrm{~m}$ and $1 \mathrm{~m}$

Another interesting comparation was made with the noise level values fromall systems, including the values without panels. This comparation can be observed in Fig. 11 and Fig. 12. A first comment here will be regarding the role of the panelsin these acoustic measurements. It can be observed that the panels attenuate the noise and 
the valuesare decreasing greatly with them mounted on the UAF diffuser. Here we can see again the influence of the perturbing factors. Despite these perturbations, the measured values are roughly the same for all systems, with slight differences. Also, the differences between the valuesare almost equal across the entire range of flows. Thus, one can assume that either system will generate almost the same noise and it has noreason to choose one instead of another.

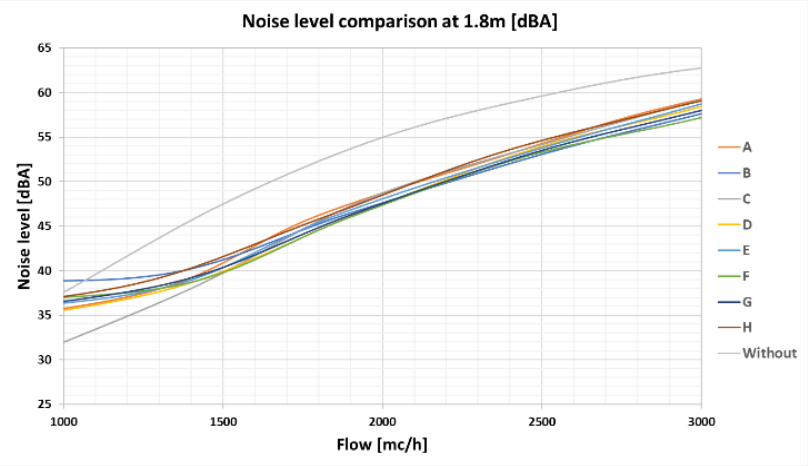

Figure 11. Noise comparation for all systems, $1.8 \mathrm{~m}$ height

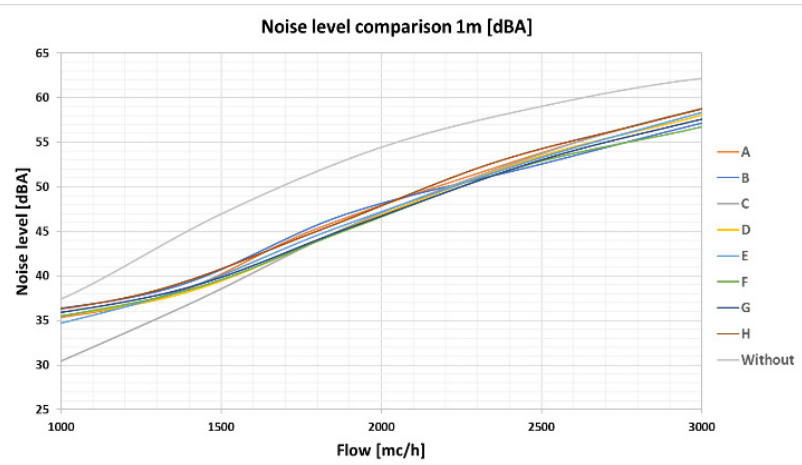

Figure 12. Noise comparation for all systems, $1 \mathrm{~m}$ height

The pressure loss values obtained for all systems were compared and can be seen in Fig. 13. It can beobserved here that there is a threshold around the value of 2000 $\mathrm{mc} / \mathrm{h}$. Before this value, there are very small differences between the systems. After this value, the system with panel type $\mathrm{E}(,, \Delta$ ") and $\mathrm{D}(,, \square$ ") tends to generate more pressure loss then the others. The difference between the system with panel type E, D and the next one, panel type A (,,+ intercalated"), is around9-10Pa.

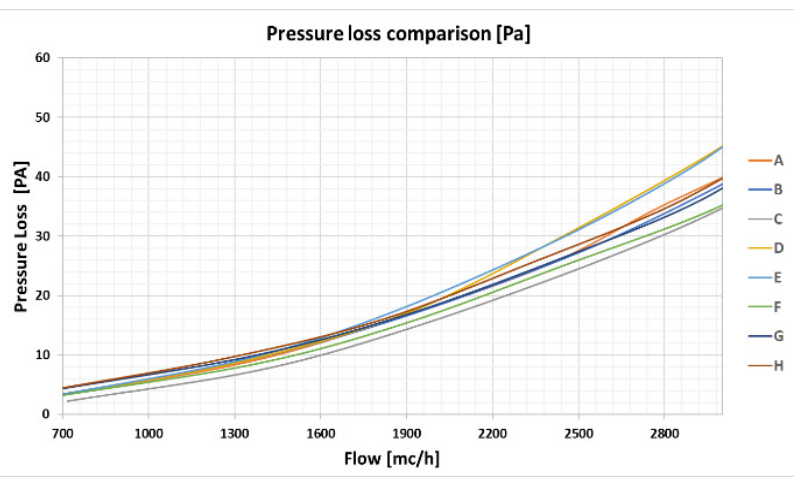

Figure 13. Pressure loss comparation

The other 6 systems tend to keepthe same differences between values even after this threshold. For this parameter, one can assume that you should avoid a system with type E panel, while a better solution will be a system with type C (,O”) or F (,x intercalated”).

A comparation with all the technical parameters was made in Table II and III. For determining the pressure loss and the noise level which corresponds to the 3 flow rates that were chosen, interpolations were made based on the values obtained from measurements. The velocity was calculated for eachflow by knowing the free flow surface of a geometry and the total number of geometries in a panel, resulting free flow area.

TABLE I. Technical parameters, same flow, panels $\mathrm{A} \div \mathrm{D}$

\begin{tabular}{|c|c|c|c|c|c|c|}
\hline$V(\mathrm{~m} / \mathrm{s})$ & $Q\left(m^{3} / h\right)$ & & Panel A $\left({ }^{\prime},{ }^{\prime \prime}\right.$ i) & Panel B (, $x^{\prime \prime}$ L) & Panel C („, $\left.\mathrm{O}^{\prime \prime}\right)$ & Panel D („口") \\
\hline \multirow{3}{*}{0.43} & \multirow{3}{*}{700} & $\mathrm{~h}(\mathrm{~Pa})$ & 3.1 & 3.4 & 2.3 & 3.0 \\
\hline & & Lp (dBA 1.8m) & 33.9 & 38.7 & 28.0 & 33.7 \\
\hline & & Lp (dBA 1m) & 33.6 & 35.0 & 26.2 & 34.0 \\
\hline \multirow{3}{*}{0.93} & \multirow{3}{*}{1500} & $\mathrm{~h}(\mathrm{~Pa})$ & 10.4 & 11.2 & 9.7 & 11.7 \\
\hline & & Lp (dBA 1.8m) & 40.5 & 41.7 & 40.9 & 40.6 \\
\hline & & Lp (dBA 1m) & 39.8 & 41.1 & 39.5 & 40.1 \\
\hline \multirow{3}{*}{1.85} & \multirow{3}{*}{3000} & $\mathrm{~h}(\mathrm{~Pa})$ & 35.8 & 38.8 & 36.7 & 44.8 \\
\hline & & Lp (dBA $1.8 \mathrm{~m})$ & 57.7 & 57.6 & 59.9 & 58.3 \\
\hline & & $\operatorname{Lp}(\mathrm{dBA} 1 \mathrm{~m})$ & 57.2 & 57.1 & 59.5 & 58.0 \\
\hline Aff $\left(m^{2}\right)=$ & 0.45 & Sff $\left(\mathrm{mm}^{2}\right)=$ & 19.625 & & & \\
\hline
\end{tabular}

TABLE II. Technical parameters, same flow, panels $\mathrm{E} \div \mathrm{H}$

\begin{tabular}{|c|c|c|c|c|c|c|}
\hline$V(\mathrm{~m} / \mathrm{s})$ & $Q\left(m^{3} / h\right)$ & & Panel E $\left(, \Delta^{\prime \prime}\right)$ & Panel F (,, $\mathbf{x}^{\prime \prime}$ i) & Panel G $\left({ }_{(1}+x^{\prime \prime}\right)$ & Panel H (, (, ${ }^{\prime \prime}$ L) \\
\hline \multirow{3}{*}{0.43} & \multirow{3}{*}{700} & $h(\mathrm{~Pa})$ & 3.1 & 3.2 & 4.2 & 4.2 \\
\hline & & $\operatorname{Lp}(\mathrm{dBA} 1.8 \mathrm{~m})$ & 35.1 & 36.4 & 35.1 & 35.5 \\
\hline & & Lp (dBA 1m) & 31.9 & 33.7 & 34.2 & 34.7 \\
\hline \multirow{3}{*}{0.93} & \multirow{3}{*}{1500} & $\mathrm{~h}(\mathrm{~Pa})$ & 11.6 & 10.5 & 11.9 & 11.3 \\
\hline & & Lp (dBA 1.8m) & 40.6 & 40.7 & 41.0 & 41.0 \\
\hline & & Lp (dBA 1m) & 40.1 & 40.3 & 40.4 & 40.2 \\
\hline \multirow{3}{*}{1.85} & \multirow{3}{*}{3000} & $h(\mathrm{~Pa})$ & 42.5 & 35.8 & 37.2 & 35.7 \\
\hline & & Lp (dBA 1.8m) & 57.9 & 57.4 & 57.6 & 57.7 \\
\hline & & $\operatorname{Lp}(\mathrm{dBA} 1 \mathrm{~m})$ & 57.5 & 57.0 & 57.3 & 57.3 \\
\hline Aff $\left(m^{2}\right)=$ & 0.45 & $\mathrm{Sff}\left(\mathrm{mm}^{2}\right)=$ & 19.625 & & & \\
\hline
\end{tabular}

\section{Conclusions}

This study allowed us to obtain the technical parameters of this panelsand the ventilation system and represents a first step in the attempt to research how these geometries influences the air distribution in the enclosure.

Some conclusions can be drawn on the values obtained from the measurement campaign presented in this paper. Regarding the noise measurement values, one can say that no significantdifferences are between the values obtained at different heights, and the noise produced by the system will be perceived almost the same for both patient $(\approx 1 \mathrm{~m})$ and surgeon $(\approx 1.8 \mathrm{~m})$. Another conclusion that can be drawn is that almost no differences were observed for noise levels generated by the different systems. Anobservationwhich cannot be overlooked is the fact that any panelattenuates the noise produce by the fan.

Regarding the pressure loss measurements, it was confirmed that some geometries, which were expected to

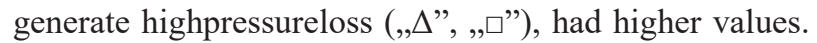
Also, it was observedthat the special geometries didn't generate high pressure loss at high flow rates, some even getting good results (,x”i. or ,,+” L.).

More research must be done in this fieldfor abetter understanding.Future research can study the influences of perforated panels on thermal comfort felt by the occupants, aerosol distribution in the room, energy consumption of the system.

This work was supported by a grant of the Romanian space agency ROSA, QUEST - Advanced air diffusion system of the 
crew quarters for the ISS and deep space habitation systems, STAR-CDI-C3-2016-577

\section{References}

1. Koufi L, Younsi Z, Cherif Y, Naji H. Numerical investigation and analysis of indoor air quality in a room based on impinging jet ventilation. Energy Procedia;139:710-7 (2017)

2. Kandzia C, Kosonen R, Melikov AK, Nielsen PV. Mixing Ventilation. Guide on mixing air distribution design. Müller D, editor: Federation of European Heating and Air-Conditioning Associations, REHVA; (2013)

3. Awbi HB. Ventilation for Good Indoor Air Quality and Energy Efficiency. Energy Procedia;112:277-86 (2017)

4. Fischer S, Thieves M, Hirsch T, Fischer K-D, Hubert H, Bepler S, et al. Reduction of Airborne Bacterial Burden in the OR by Installation of Unidirectional Displacement Airflow (UDF) Systems. Medical Science Monitor : International Medical Journal of Experimental and Clinical Research;21:2367-74 (2015)

5. Yang C, Yang X, Zhao B. The ventilation needed to control thermal plume and particle dispersion from manikins in a unidirectional ventilated protective isolation room. Building Simulation;8(5):551-65 (2015) 6. Heather C. Willis Whitfield, inventor of modernday laminar-flow clean room, passes away. Sandia Lab News, Vol 64, 16:8 (2012.11)

7. Nastase I, Croitoru C, Dan M, Ursu I, Meslema A. Experimental Study for the integration of an Innovative Air Distribution System in Operating Rooms. Sustainable Solutions for Energy and Environment, EENVIRO 2016; 26-28 October 2016; Bucharest, Romania (2016)

8. Nastase I. Strategii performante pentru creșterea calităţii ambientale în sălile de operație (EQUATOR). UTCB (2016)

9. Meslem A, Nastase I, Allard F. Passive mixing control for innovative air diffusion terminal devices for buildings. Building and Environment;45:2679-88 (2010) 